This paper is published in the open archive of Mid Sweden University

DIVA http://miun.diva-portal.org

with permission of the publisher

Citation for the peer-reviewed published paper:

Fjellström H, Höglund H, Forsberg S, Paulsson M. Inhibition of lightinduced brightness reversion of high-yield pulps : the UV-screening properties of coating layers containing kaolin or calcium carbonate pigments. ; Nordic Pulp \& Paper Research Journal. 2007;22(3):350-355.

URL to article at publishers site:

http://dx.doi.org/10.3183/NPPRJ-2007-22-03-p350-355 


\title{
Inhibition of light-induced brightness reversion of high-yield pulps: The UV-screening properties of coating layers containing kaolin or calcium carbonate pigments
}

\author{
Helena Fjellström, Hans Höglund and Sven Forsberg, Mid Sweden University, Sundsvall, Sweden, Magnus Paulsson, Eka Chemicals AB, Bohus, \\ Sweden
}

KEYWORDS: High-yield pulp, CTMP, Birch, Coating, Pigments, Kaolin, Calcium carbonate, Light-induced, Ageing

\begin{abstract}
SUMMARY: A newly developed method making it possible to study the reflectance/transmittance factor of thin coating layers and to link this to the inhibition of the light-induced yellowing, was used to describe the photo-stabilising properties of different types of commercial kaolin and calcium carbonate pigments. A base paper produced from a hydrogen-peroxidebleached birch chemithermomechanical pulp (CTMP) was used throughout the study.

The transmittance factor of the coating layers in the UVregion (300-385 nm) was found to be very low (below 1.0\% at coat weights $>5 \mathrm{~g} / \mathrm{m}^{2}$ ) for all of the tested pigments, it strongly depends on the coat weight especially for coat weights below 10 $\mathrm{g} / \mathrm{m}^{2}$. The examined coating colours containing kaolin pigments were found to be better in inhibiting the brightness reversion compared to the coating colours containing calcium carbonate pigments, even though the differences between the pigment types in the coating colours were only a few brightness units. The coating layer was, however, able to conceal some of the colour formed through the light-induce brightness reversion. For example, a coating layer containing kaolin pigments (coat weight of $15.6 \mathrm{~g} / \mathrm{m}^{2}$ ) could conceal about $30 \%$ of the discoloration of the CTMP base paper, when measuring the change in ISO brightness.
\end{abstract}

\footnotetext{
ADDRESSES OF THE AUTHORS: Helena Fjellström

(helena.fjellstrom@miun.se), Hans Höglund (hans.hoglund@ miun.se) and Sven Forsberg (sven.forsberg@miun.se): Mid Sweden University, Fibre Science and Communication Network, FSCN, Department of Natural Science, Holmgatan 10, SE-851 70 Sundsvall, Sweden. Magnus Paulsson (magnus. paulsson@eka.com): Eka Chemicals AB, SE-445 80 Bohus, Sweden. Corresponding author: Helena Fjellström
}

With modern production technologies high-yield pulps can be produced with mechanical and optical properties rendering them suitable to be the major constituents of many grades of paper. The rapid brightness reversion (yellowing) that occurs upon exposure to daylight or indoor illumination is, however, a major drawback hindering mechanical or chemimechanical pulps to be used in high-quality long-life paper products. It is generally accepted that it is the lignin constituents that are responsible for the brightness reversion that occurs when the paper is subjected to sunlight or indoor illumination containing UV-radiation (Gratzl 1985; Heitner 1993; Leary 1994; Davidson 1996; Forsskåhl 2000; Lanzalunga, Bietti 2000). In addition, additives like FWA and binders also can contribute to the brightness reversion (Rohringer, Fletcher 1996; Paulsson, Ragauskas 1998a). Yet, no satisfying (i.e. cost-efficient, technically feasible, nontoxic) solution that could efficiently slow down the yellowing rate for uncoated paper grades has been discovered. Coating of paper has, however, the potential to retard the discoloration and is most likely necessary for photo-stability reasons if pulps containing lignin are to be used as the main fibre-furnishing component in long-life and high-value products.

The amount and type of pigments in the coating colour can vary from relatively low-cost natural mineral pigments (e.g. kaolin clay, calcium carbonate, talc) to synthetic inorganic or organic products (e.g., plastic and silica type products). It is well known that factors like pigment type, particle size distribution, coat weight, coating additives, and the homogeneity of the coating layer greatly influence the photo-stability (Fossum et al. 1976; Gellerstedt et al. 1983; Lindblad et al. 1989; Johnson 1989, 1991; El-Sadi et al. 2002; Ghosh et al. 2002; Yuan et al. 2003, 2006). Kaolin clay has been reported to be somewhat more effective in retarding the accelerated (xenon lamp) light-induced yellowing compared to a coating layer containing calcium carbonate pigments (Fossum et al. 1976). Substitution of some of the kaolin with $\mathrm{TiO}_{2}$ was shown to improve the photo-stability of the TMP-containing paper. Luo and Göttsching (1991) reported that kaolin was somewhat more effective in retarding the photo-yellowing of a base paper intended for light weight coated paper grades than a brighter calcium carbonate pigment. They also found that when combining kaolin and calcium carbonate pigments, the performance where improved to some extent (Luo and Göttsching 1991). On the other hand, Krogerus and Forsskåhl (1995) found calcium carbonate to be superior to other pigments in light-induced ageing experiments.

According to Johnson (1991), coating a hydrogen-peroxide-bleached CTMP with a coat weight of about $4 \mathrm{~g} / \mathrm{m}^{2}$ of clay gives $20 \%$ brightness stabilisation against accelerated (sunlamps) light-induced yellowing. The brightness stabilisation could be increased to $60 \%$ by using kaolin: $\mathrm{TiO}_{2}$ in the ratio 80:20. Yuan et al. (2006) reported that a coated (calcium carbonate/delaminated clay, 20 $\mathrm{g} / \mathrm{m}^{2}$ ) kraft sheet with a $15 \%$ substitution of bleached birch CTMP gave the same brightness stability as a $100 \%$ kraft sheet coated at $4 \mathrm{~g} / \mathrm{m}^{2}$. The evaluation was made using both accelerated (fluorescent lamps) and natural long-term light-induced ageing. The binders and thickeners in the coating colour also effect the brightness stability (Luo, Göttsching 1991; Reinhardt, Arneberg 1988), for example, polyester-polynitrile is more photostable than butadiene-styrene.

The particle size distribution of the pigment is known to have an effect on the light scattering ability (Bown 1997; Lindblad et al. 1989). A steep particle size 
distribution gives higher porosity and has the advantage of creating void space in the dried structures and hence could enhance the light scattering. If maximum light scattering is desired in a certain wavelength region (e.g., the UV-region) the pore diameter should be of a magnitude such that the ratio of pore diameter to wavelength is approximately 0.5 and preferably all the pores should be of the same size (Lindblad et al. 1989). A monodisperse pigment particle system of this type could offer a high UV-scattering ability that could improve the photo-stability considerably. The influence of particle size and distribution of commercial coating pigments on the UV-screening properties of coating layers are therefore important to examine.

The present paper describes the photo-stabilising properties of different types of kaolin and calcium carbonate pigments in a coating colour. A newly developed method has made it possible to study the reflectance/transmittance factor of thin coating layers and to link this to the inhibition of the light-induced yellowing (Fjellström et al. 2007). The possibility to inhibit the photo-yellowing of a hydrogen-peroxidebleached birch chemithermomechanical (CTMP) paper with coating colours containing various commercial kaolin and calcium carbonate pigments is exemplified.

\section{Materials and Methods}

\section{Pulp and paper samples}

A hydrogen-peroxide-bleached birch chemithermomechanical pulp, CTMP (2\% $\left.\mathrm{NaOH}, 3 \% \mathrm{Na} 2 \mathrm{SO}_{3}\right)$, with a brightness of $79.3 \%$ ISO and a freeness of $400 \mathrm{ml} \mathrm{CSF}$ was used as base paper. Commercially produced elemental chlorine free (ECF)-bleached birch kraft pulp with an ISO brightness of 85.0 was used as a reference in the photo-ageing studies. Both pulps were manufactured at SCA Östrand, Sweden.

The light weight coated (LWC) paper used in the study was commercially produced and was received from SCA Ortviken, Sundsvall, Sweden. The LWC base paper consisted of $30 \% \mathrm{kraft}$ and $70 \%$ hydrogen-peroxidebleached softwood TMP. The basis weight of the coated paper was $80 \mathrm{~g} / \mathrm{m}^{2}$. The coating colour contained both kaolin and calcium carbonate pigments and also some fluorescent whitening agent (FWA).

\section{Preparation of paper sheets}

Paper sheets with a grammage of $70 \mathrm{~g} / \mathrm{m}^{2}$ were produced on a small experimental paper machine (XPM, MoRe Research, Örnsköldsvik, Sweden) with a head box width of $0.225 \mathrm{~m}$ and a machine speed of $0.5-3.0 \mathrm{~m} / \mathrm{min}$. The fibre furnish consisted of $100 \%$ hydrogen-peroxidebleached birch CTMP. The filler (Syndcarb F0474-MJ, PCC; Omya AB) content of the paper sheets was $20 \%$. The Hydrocol system (Hydrocol 878, 0.01\%; Hydrocol $\mathrm{SH}, 0.06 \%$, Ciba Specialty Chemicals) was used as the retention system, and ASA as internal size (Kemsize 200, $0.08 \%$, Sellukem). The starch for the wet-end (Raiso R142, 0.50\%; Raiso Chemicals) was splitted; $0.3 \%$ was added to the stock and $0.2 \%$ to the ASA. The produced papers were surface sized ( $C^{*}$ size 05962, 2.86\%, Cerestar) and had an ISO brightness of $79.3 \%$.

\section{Coating pigments}

Eight pigments with various particle shape, particle size, particle size distribution (psd) and light scattering characteristics were obtained from Imerys, UK. The four clays, (Supragloss 95, Astra-Sheen, Astra-Plus and Alphatex) and four carbonates (Carbital 60, Carbital 95, Carbopaque 90 and Opti-Cal Print 400) were used as received. All carbonates were ground marble (i.e., GCCs) except for Opti-Cal Print 400 that was a precipitated calcium carbonate (PCC). One of the clays was calcined, (Alphatex). Supragloss 95 is a clay with fine particle size. Astra-Sheen is an US clay with a broad psd, low light scattering and an ultra fine particle size. Astra-Plus is an US clay with a steep pigment size distribution, higher light scattering and a fine particle size. Alphatex is a calcined clay and has a very high light scattering ability. Carbital 60 is coarse whilst Carbital 95 is ultrafine. Carbopaque 90 has a steep psd, higher light scattering, and a fine particle size. Opti-Cal Print 400 is a precipitated calcium carbonate with a very high light scattering ability. More information about the kaolin clays and calcium carbonate pigments used can be found in Table 1 and Fig 1.

\section{Coating procedure}

Quartz glass plates were coated in a laboratory coater using a glass rod to spread the coating colour. To obtain various coat weights the speed of the glass rod was varied. The coating layer was dried at room temperature before UV-VIS spectroscopic analysis.

The base coating consisted of a pigment (100 parts), styrene butadiene latex (8 parts, DL920, Dow) and carboxymethylcellulose ( 0.5 parts, FF10, Noviant). The $\mathrm{pH}$ of the coating colour was adjusted to 8.5. The basis weight $\left(\mathrm{g} / \mathrm{m}^{2}\right)$ of the coating layer was determined as previously reported in Fjellström et al. (2007).

\section{UV-VIS diffuse reflectance factor spectroscopy}

As for the majority of optical instruments, the measured values are not the total amount of light reflected or transmitted in every direction, but a well defined fraction of it. To account for the specific conditions set by the instrument and the procedures, the optical values are referred to as transmittance factors or reflectance factors.

UV-VIS spectra were recorded on a UV-Visible spectrophotometer (Varian Cary 100 Bio.) Spectral data were obtained by changing the wavelength of the illumination from 200-700 nm in steps of $1 \mathrm{~nm}$. The scan rate was 600 $\mathrm{nm} / \mathrm{min}$. The resulting spectra for each sampling point are mean values from at least 3 measurements.

For detailed information of the UV-VIS diffuse reflectance factor spectroscopy measurements, see Fjellström et al. (2007).

\section{Accelerated light-induced ageing}

The accelerated ageing of the paper samples was performed with a Xenotest 150 (Heraeus, Hanau, Germany) equipped with a xenon lamp and with filters (ultraviolet 
Table1. Information about the pigments used (data obtained from Imerys).

\begin{tabular}{|c|c|c|c|c|c|c|c|c|c|}
\hline Pigment & $<2 \mu \mathrm{m}$ & $<1 \mu \mathrm{m}$ & $\mathrm{Wt} \%<0,5 \mu \mathrm{m}$ & $<0,25 \mu \mathrm{m}$ & $<0,10 \mu \mathrm{m}$ & $\mathrm{D} 50 \mu \mathrm{m}^{3)}$ & Surface area $\left(\mathrm{m}^{2} / \mathrm{g}\right)$ & Shape factor & Brightness (\% ISO) \\
\hline \multicolumn{10}{|l|}{ Kaolin clays } \\
\hline Alphatex ${ }^{11}$ & 90 & 80 & 40 & 6 & ก.a. ${ }^{4)}$ & 0.60 & 13 & n.a. ${ }^{4)}$ & 91.6 \\
\hline Supragloss952) & 91 & 75 & 55 & 28 & 15 & .46 & 16 & Platy (30-35) & 86.8 \\
\hline Astra-Plus & 93 & 78 & 52 & 23 & 4 & 0.49 & 13 & Platy (10-15) & 86.9 \\
\hline Astra-Sheen & 99 & 97 & 90 & 61 & 28 & 0.31 & 27 & Platy (10-15) & 88.7 \\
\hline \multicolumn{10}{|l|}{ Calcium carbonates } \\
\hline Opti-Cal Print 400 & 97 & 95 & 75 & 18 & ก.a. ${ }^{4)}$ & 0.37 & 9 & n.a. ${ }^{4)}$ & 95.8 \\
\hline Carbopaque $90^{21}$ & 88 & 60 & 26 & 12 & n.a. ${ }^{4)}$ & 0.80 & 11 & Blocky & 95.4 \\
\hline Carbital $95^{2)}$ & 95 & 80 & 50 & 30 & 15 & 0.45 & 15 & Blocky & 94.5 \\
\hline Carbital $60^{22}$ & & 60 & 35 & 20 & & & & Blocky & \\
\hline
\end{tabular}

1) Alphatex is a calcined and is aggregated. The paricle size distribution measured by Sedigraph assumes that the particles have a density of $2.65 \mathrm{~g} / \mathrm{cm}^{3}$. However, the aggregates will have a pore structure which will be filled with water hence lowering the effective particle density to somewhere between $1.00 \mathrm{and} 2.65 \mathrm{~g} / \mathrm{cm}^{3}$.Hence the real aggregate size distribution will be coarser than reported here.

2) Typical data obtained from Imerys.

3) Mean particle size.

4) Not available

and window glass), which eliminate radiation of wavelengths below $310 \mathrm{~nm}$. The temperature was kept close to room temperature by means of a cooling fan. An optical sensor, compensating for possible main voltage fluctuations and lamp ageing, controlled the irradiance. The irradiance in the UV-A region was about $40 \mathrm{~W} / \mathrm{m}^{2}$. The spectral characteristics of the transmitted light are similar to those of average indoor daylight (sunlight behind window glass, cf. Paulsson, Ragauskas 1998).

\section{Standard Optical measurements}

ISO brightness of the paper samples was measured using an Elrepho SE 071 spectrophotometer (Lorentzen \& Wettre) in accordance with ISO standard method 2470. An opaque pile of unaged base paper was used as background.

\section{Results and Discussion}

\section{Characterisation of the pigments}

Table 1 shows some characteristic properties (brightness, particle size and distribution and aspect ratio) of the kaolin and calcium carbonate pigments used in this work. The pigments chosen represent commercial pigments with a surface area of $9-27 \mathrm{~m}^{2} / \mathrm{g}$. Astra-Sheen and AstraPlus are fine American clays and are usually used in top coatings. Alphatex is heat treated (calcinated) which makes it porous and hence, it has a very high light scattering ability. Alphatex is more expensive than regular clays and it is only used in relatively small amounts in coating and filler applications. Carbital 60 is used as filler and in pre coatings, while Carbital 90, Carbital 95 and Opti-Cal Print 400 mostly are used in top coating.

The kaolin clay pigments are platy flake like particles, with the exception of Alphatex, which is a calcined clay and thus consisting of very small pigment particles that are aggregated. Opti-Cal Print 400 which is a precipitated calcium carbonate, (PCC), consists of many small pigment particles that are aggregated into relatively blocky aggregates that give a low surface area. The other calcium carbonates are ground marbles, (GCCs, ground

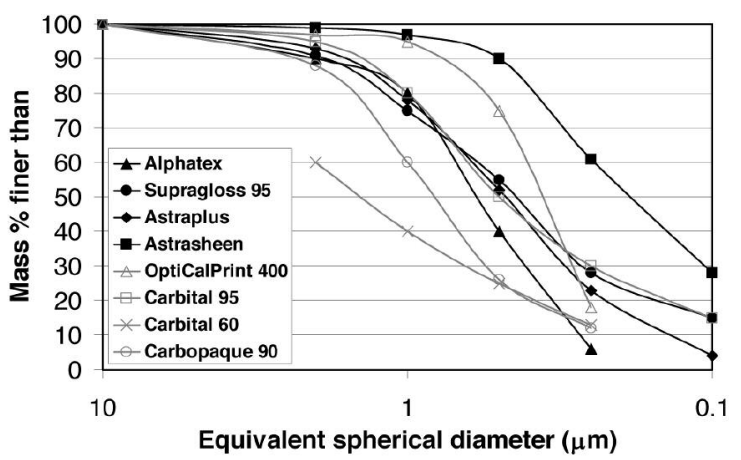

Fig 1. The pigment size distribution for the kaolin (Alphatex, Supragloss 95, AstraPlus, Astra-Sheen) and calcium carbonate (Opti-Cal Print 400, Carbital 95, Carbital 60, Carbopaque 90) pigments used. (Data from Table 1.)

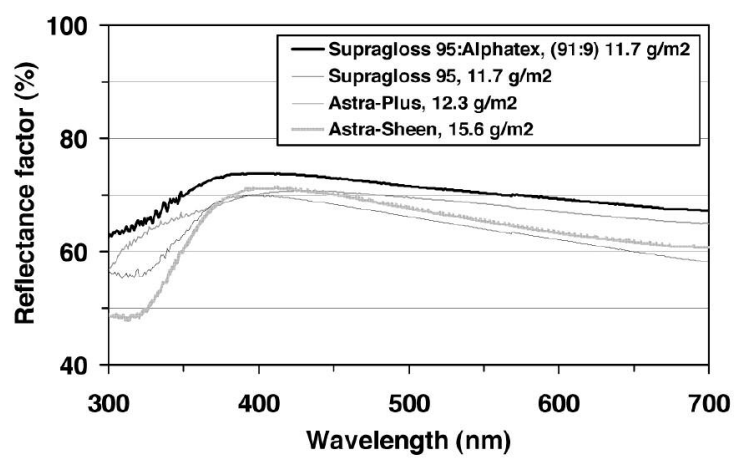

Fig 2. The reflectance factor in the UV-VIS region 300-700 $\mathrm{nm}$ for the coating colours containing kaolin pigments used in this investigation.

calcium carbonates), and are therefore blocky sphere like pigments. Kaolin clays generally have a lower brightness (4-9 brightness units) than the calcium carbonates, (cf. Table 1) mainly due to their higher light absorption ability (Bown 1997).

The reflectance factor in the UV-VIS region (300-700 $\mathrm{nm}$ ) for the four coating colours containing kaolin clay pigments used in this investigation is given in Fig 2. Only curves with approximately the same coat weight can be compared directly, since the curves will be moved upward/downward with increasing/decreasing coat weight. However, the shape of the curves can be compared despite differences in the coat weight. The clay pigment coating colours differ most in reflectance factor 


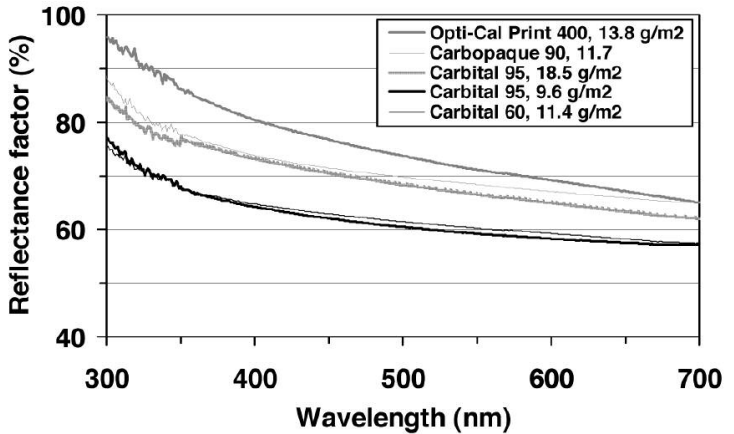

Fig 3. The reflectance factor in the UV-VIS region 300-700 nm for the coating colours containing calcium carbonate pigments used in this investigation. The influence of coat weight is illustrated for the Carbital 95 pigment (reflectance factor curves given at 9.6 and $18.5 \mathrm{~g} / \mathrm{m}^{2}$ ).

in the UV-region (300-400 nm), where Astra-Sheen has the steepest curve and Supragloss 95 has the most flat one.

In Fig 3 the reflectance factor for the coating colours containing calcium carbonate pigments are shown between 300-700 $\mathrm{nm}$. The shapes of the curves are about the same regardless of the type of calcium carbonate pigment used. The influence of coat weight is illustrated for Carbital 95, i.e., that the reflectance factor curves are shifted upwards when increasing the coat weight. Carbopaque 90 with a fine pigment size and a steep particle size distribution (psd) reflects about $10 \%$ more light in the UV-region compared to Carbital 60 that has a coarse pigment size and broader psd.

When comparing the kaolin clays and the calcium carbonates, it is evident that they differentiate the most in the UV-region (300-400 nm). Below $400 \mathrm{~nm}$, the kaolin clays are declining in reflectance factor when going down in wavelength, whilst the calcium carbonates increase their reflectance factor. This is in agreement with previously reported results (cf. e.g., Johnson 1991, Fjellström et al. 2007). The low reflectance factor of the kaolin clays in the UV-region is probably due to their higher light absorption ability (cf. Bown 1977). A high ability to absorb light in the UV-region also implies a low transmittance in the same region.

\section{Transmittance in the UV-region (300-385 $\mathbf{~ m})$}

Figs 4-5 shows the transmittance factor in the 300-385 $\mathrm{nm}$ region of coating colours containing kaolin or calcium carbonate pigments. The UV-region 300-385 nm was chosen since it has been proposed that the transition from photo-yellowing to photo-bleaching of lignocellulosic materials occurs at wavelengths around $385 \mathrm{~nm}$ (cf. e.g. Nolan et al. 1945; Leary 1967; Andtbacka 1989; Mailly et al. 1996). The transition is, however, not fixed to a certain wavelength but depends on several things such as e.g., wood raw material and pulping method used (cf. Heitner 1993).

When comparing the results in Figs 4-5, it is clear that the kaolin pigments have a somewhat lower transmittance factor in the UV-region (300-385 nm) compared to the calcium carbonate pigments. It is also evident that the differences between the various kaolin pigments and the different calcium carbonate pigments are minor. The coating colours containing kaolin clays lower the trans-

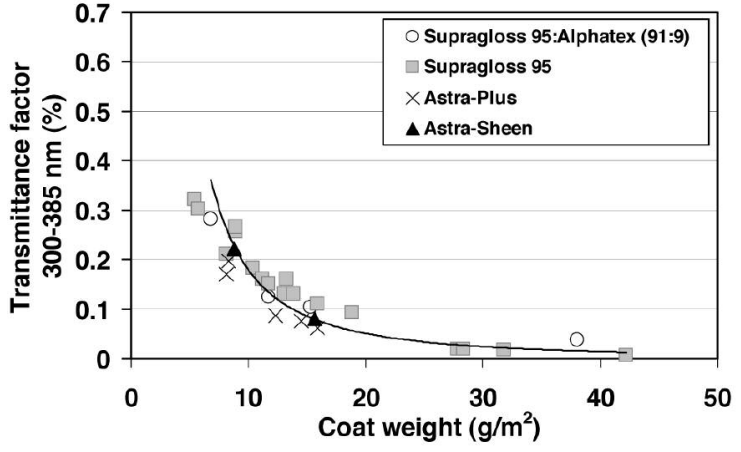

Fig 4. The transmittance factor in the $300-385 \mathrm{~nm}$ region of coating colours containing kaolin pigments.

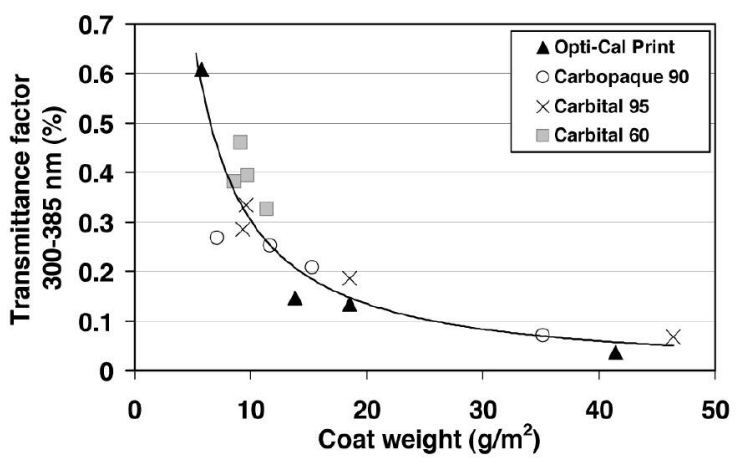

Fig 5. The transmittance factor in the $300-385 \mathrm{~nm}$ region of coating colours containing calcium carbonate pigments.

mittance factor with $0.1-0.15 \%$ more than the coating colours containing calcium carbonates, when coated with $7-20 \mathrm{~g} / \mathrm{m}^{2}$. This suggests that the kaolin pigments used have a better photo-protecting ability compared to the coating colour based on calcium carbonate pigments. However, the transmittance factor in the UV-region is generally very low (below $1.0 \%$ at coat weights $>5 \mathrm{~g} / \mathrm{m}^{2}$ ) for all of the tested pigments and strongly dependent of the coat weight, especially for low coat weights (below $10 \mathrm{~g} / \mathrm{m}^{2}$ ). The very strong dependence on coat weight indicates that an even coating layer is crucial, at least at low coat weight, to inhibit brightness reversion

\section{Photo-yellowing of coated birch $\mathrm{H}_{2} \mathrm{O}_{2}$-bleached CTMP}

The hydrogen-peroxide-bleached birch CTMP base paper was placed behind the coated quartz glass plates and then subjected to accelerated light-induced ageing simulating indoor daylight according to a previously described procedure (Fjellström et al. 2007). Figs 6-7 shows the change in ISO brightness (of the base paper) after 24 hours of accelerated light-induced irradiation. Over all, the brightness loss decreased with an increase in coat weight, independent of pigment types used. The kaolin pigments examined were found to be slightly better in photo-stabilising the base paper compared to the calcium carbonate pigments, even though the differences are only a few brightness units. At a coat weight of about $12 \mathrm{~g} / \mathrm{m}^{2}$, the brightness loss of the base paper is about five brightness units lower when coated with coating colours containing kaolin clay pigments compared to when coated with coating colours containing calcium carbonate pigments. Also, the difference in brightness loss, between the coating colours containing kaolin and the coating colours 


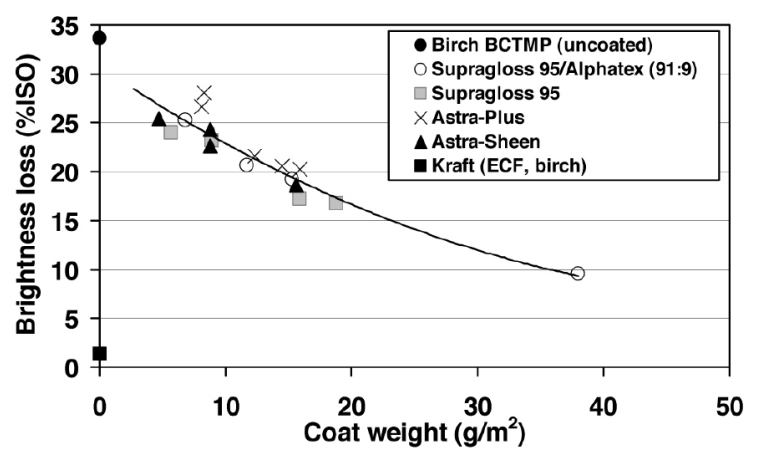

Fig 6. The change in ISO brightness after accelerated light-induced ageing for 24 hours of uncoated and kaolin coated hydrogen-peroxide-bleached birch CTMP. The ageing of the coated papers was performed according to the method previously described, i.e., the brightness loss is the brightness loss of the base paper (cf. Fjellström et al. 2007). The ageing characteristic of an ECF-bleached birch kraft pulp is given as a reference.

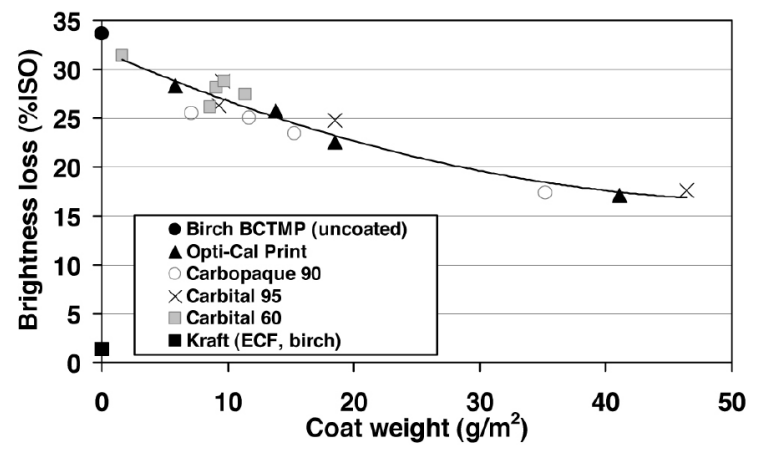

Fig 7. The change in ISO brightness after accelerated light-induced ageing for 24 hours of uncoated and calcium carbonate coated hydrogen-peroxide-bleached birch CTMP. The ageing of the coated papers was performed according to the method previously described, i.e., the brightness loss is the brightness loss of the base paper (cf. Fjellström et al. 2007). The ageing characteristic of an ECF-bleached birch kraft pulp is given as a reference.

containing calcium carbonate pigments, increases with increasing coat weight (cf. Figs 6-7).

The brightness loss in Fig 6 and 7 were calculated from the measurements made on the base paper only. In reality, the coating layer itself will also contribute to the optical properties of the paper, i.e., the coating layer can disguise the colour formed through the light-induced brightness reversion to some extent. The concealing ability of the coating layer depends on the coat weight and coating colour formulation. To investigate the impact of a coating layer, the brightness of a hydrogen-peroxide-bleached birch CTMP base paper was measured before and after 24 hours of accelerated light-induced ageing. Four quarts glass plates were coated with a coating colour containing Supragloss 95 (kaolin), and the base paper was measured again with the quartz glass plate (one at the time) in front (the coating layer was facing the base paper), see Fig 8. The brightness reversion decreased with about $30 \%$ when the base paper was measured behind a coating layer with a coat weight of $15.6 \mathrm{~g} / \mathrm{m}^{2}$. Increasing the coat weight (up to $20.6 \mathrm{~g} / \mathrm{m}^{2}$ ) only marginally influenced the concealing ability of the coating layer. The ageing characteristic of a commercial LWC paper is included in Fig 8 for comparison. The LWC paper was found to be somewhat more brightness stable which partly could be due to the fact that the base paper used in this investigation contains $100 \%$ chemimechani-

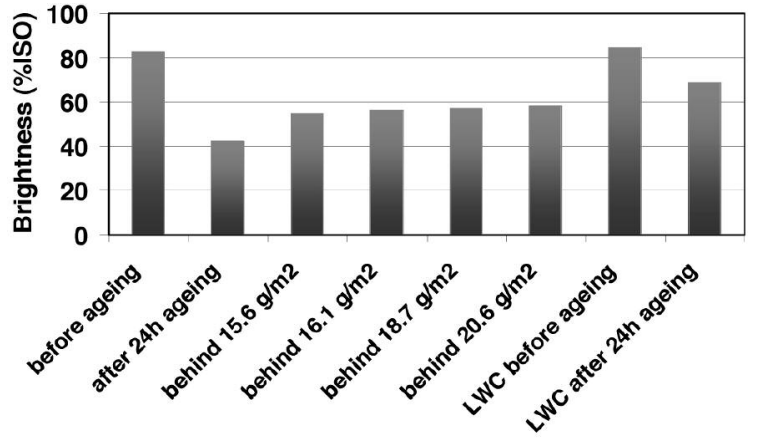

Fig 8. Brightness of the hydrogen-peroxide-bleached CTMP base paper before and after $24 \mathrm{~h}$ of accelerated light-induced ageing (before, after) and the reverted brightness measured behind coated quartz glass plates, with the coated side facing the base paper while measuring (behind). The coating colour contained the kaolin pigment Supragloss 95. The extent of photo-yellowing of an LWC paper, aged under the same conditions, is included in the figure for comparison.

cal pulp, whereas the LWC base paper only contains $70 \%$ mechanical pulp. The coating colour also contained some FWA that could increase the photo-stability of the LWC base paper.

\section{Conclusions}

Coating colours containing kaolin pigments have a somewhat lower transmittance factor in the UV-region (300-385 nm) than coating colours containing calcium carbonate pigments. The differences between the different commercial kaolin and calcium carbonate coating colours were, however, minor. The transmittance factor characteristics of the coating colours are in agreement with the fact that the kaolin coating colours were better in photo-stabilising the hydrogen-peroxide-bleached birch CTMP base paper compared to the calcium carbonate coating colours, even though the differences were only a few brightness units. At a coat weight of about $12 \mathrm{~g} / \mathrm{m}^{2}$, the brightness of the base paper was about five brightness units higher when coated with coating colours containing kaolin clay pigments than coated with coating colours containing calcium carbonate pigments. The photostability was improved with an increase in coat weight independent of pigment types used.

Coating layers are able to conceal the colour formed during light-induce brightness reversion to some extent depending on the coating colour composition and applied coat weight. A coating layer consisting of kaolin pigments (coat weight of $15.6 \mathrm{~g} / \mathrm{m}^{2}$ ) could conceal about $30 \%$ of the discoloration of the birch CTMP base paper.

\section{Acknowledgements}

The authors would like to thank SCA Graphic Research AB, Sundsvall for valuable support. The Fibre Science and Communication Network (FSCN), EU Objective 1, the Region of South Forest Counties, The Knowledge Foundation and The Swedish Energy Agency are gratefully acknowledged for financial support.

\section{Literature}

Andtbacka, A., Holmbom, B. and Gratzl, J.S. (1989): Factors influencing lightinduced yellowing and bleaching of spruce groundwood, 5th Int. Symp. Wood Pulp. Chem., Raleigh, NC, USA, May 22-25, Vol. 1, 347-351. 
Bown, R. (1997): A review of the influence of pigments on papermaking and coating. Fundamentals of papermaking materials, 11th Fundamental Res. Symp., Cambridge, UK, September 21-26, Editor C.F. Baker, Pira International, Leatherhead, UK Vol. 1, 83-138.

Davidson, R.S. (1996): The photodegradation of some naturally occurring polymers, J. Photochem. Photobiol. B 33(1), 3-25.

El-Sadi, H., Yuan, Z., Esmail, N. and Schmidt, J. (2002): Factors affecting the inhibition of light-induced yellowing of a coated BTMP paper, J. Pulp Paper Sci. 28(12), 400-405.

Fjellström, H., Höglund, H., Forsberg, S. and Paulsson, M. (2007): A novel method for studying the photo-stabilising properties of coating layers, Nord. Pulp Paper Res. J. 22(3), 343-349.

Forsskåhl, I. (2000): Brightness reversion, In: Forest Products Chemistry, Edited by P. Stenius, Fapet Oy, Helsinki, Finland, pp. 278-332.

Fossum, T., Lindahl, A., Rudström, L. and Smedman, L. (1976): High grade graphic paper from mechanical pulp, Pulp Paper Can. 77(2), 53-55.

Gellerstedt, G., Pettersson, I. and Sundin; S. (1983): Light-induced and heatinduced yellowing of mechanical pulps, Svensk Papperstidning, 86(15), R157R163.

Ghosh, T., Cogswell, D., Cunningham, A. and Raue, D. (2002): Inhibition of brightness reversion in coated groundwood sheets: Effect of coatweight, application method and coating ingredients, TAPPI Coating Conf., Orlando, FL, USA, May 5-8, 11 pp. (CD-Rom).

Gratzl, J.S., (1985): Lichtinduzierte Vergilbung von Zellstoffen - Ursachen und Verhütung, Papier, 39(10A), V14-23.

Heitner, C. (1993): Light-induced yellowing of wood-containing papers: An evolution of the mechanism, In: Photochemistry of Lignocellulosic Materials, Edited by C. Heitner and J.C. Scaiano, ACS Symposium Series 531, Washington, DC, USA, pp. 2-25

Janson, J. and Forsskåhl, I. (1996): Polytetrahydrofuran: A polymer that counteracts colour reversion, Nord. Pulp Paper Res. J. 11(1), 10-14.

Johnson, R.W. (1989): Brightness stability of mechanical pulps. Relating laboratory data to performance, Tappi J. 72(12), 181-187.

Johnson, R.W. (1991): CTMP in fine papers: On-machine surface treatments for improved brightness stability, Tappi J. 74(5), 209-217.

Krogerus, B. and Forsskåhl, I., (1995): Effects of filler pigments and additives on paper yellowing, PSC Communications 83, Espo0, Finland: KCL Paper Science Centre, $25 \mathrm{pp}$.

Lanzalunga, 0. and Bietti, M. (2000): Photo- and radiation chemical induced degradation of lignin model compounds, J. Photochem. Photobiol. B 56(2-3), 85108.

Leary, G.J. (1967): The yellowing of wood by light, Tappi, 50(1), 17-19.

Leary, G.J. (1994): Recent progress in understanding and inhibiting the lightinduced yellowing of mechanical pulps, J. Pulp Paper Sci. 20(6), J154-J160. Lindblad, G., Iversen, T., Bergenblad, H. and Rigdahl, M. (1989): Light scattering ability as a tool to protect paper and board against photo-oxidation, Nord. Pulp Paper Res. J. 4(4), 253-257.

Luo, C. and Göttsching, L. (1991): Technologische Massnahmen zur Verringerung der licht-induzierten Vergilbung holzhaltiger Papiere. Teil 2: Schutzwirkung von Pigmentstrichen, Wochenbl. Papierfabr. 119(17), 635-644.

Mailly, V., Le Nest, J.F., Serra Tosio, J.M. and Silvy, J. (1996): Yellowing of coated papers under the action of heat, daylight radiation and nitrogen oxide gas, TAPPI Coating Conference, Nashville, TN, USA, May 19-33, 193-202.

Nolan, P., Van den Akker, J.A. and Wink, W.A. (1945): The "fading" of groundwood by light, Paper Trade J. 121(11), 33-37.

Paulsson, M. and Ragauskas, A.J. (1998a): Chemical modification of lignin-rich paper. Part 7. Photostabilizing high-brightness aspen CTMP by combining various classes of additives and acetylation, Nord. Pulp Paper Res. J. 13(2), 124-131.

Paulsson, M. and Ragauskas, A.J. (1998b): Chemical modification of lignin-rich paper. Part 8: Effect of light source on the accelerated light-induced yellowing of untreated and acetylated high-yield pulps, Nord. Pulp Paper Res. J. 13(2), 132142.

Rohringer, P. and Fletcher, I. (1996): Spectral properties of paper treated with fluorescent whitening agents and the effects of agent application, TAPPI Coating Conf., Nashville, TN, USA, May 19-22, 239-251.

Reinhardt, B. and Arneberg, U. (1988): Die Vergilbung gestrichener Papiere unter Licht und Temperatur, Wochenbl. Papierfabr. 116 (5), 179-184, 186-187.

Yuan, Z., Schmidt, J., Gilbert, D., Aspler, J., Heitner, C, Cunkle, G. and Ghosh, T. (2003): Improving the brightness stability of a machine coated mechanical paper: A mill trial, Int. Mech. Pulp. Conf., Québec City, Québec, Canada, June 2-5, 115-123.

Yuan, Z., Schmidt, J., Heitner, C. and Zou, X. (2006): Coating improves the brightness stability of wood-free coated papers containing high-yield pulp, Tappi J. 5(1), 9-13. 